\title{
FORMATION AND DEVELOPMENT OF INNOVATIVE CLUSTERS AS A TOOL FOR INNOVATIVE ACTIVITIES OF THE REGION
}

\author{
Marina S. Lapina \\ Volgograd State University, Volgograd, Russian Federation
}

\begin{abstract}
The urgency of the need for research is due to the current trajectory of innovative development of the Russian Federation. In the article, special attention is paid to the aspect of the analysis of the factors that form the innovative potential of the Russian Federation at the meso-level. The study of foreign and domestic experience of the regional innovation clusters functioning allowed us to identify the main trends, problems of development and directions for improving innovation clusters as an instrument of innovation activity in the region. In the analytical part of the study, the analysis of the regional innovation clusters functioning (on the example of European and Asian countries) is carried out. The study identified the promotion of economic modernization through innovation and increasing the competitiveness of industry. Foreign and domestic experience in the implementation of regional innovation development strategies allows us to identify common features of the distribution of regional factors of innovation, advantages and disadvantages, prospects for the formation, implementation and improvement of development programs of innovation clusters at the meso-level. The article defines the positive impact of state incentives and support of innovation activities, the presence of a developed innovation infrastructure, as well as networking between large corporations, small firms, research institutes and the state on the socio-economic development of territories. The results of the analysis can serve as a basis for adapting successful foreign experience in the formation and development of innovation clusters in the region in order to create a competitive innovation environment of the territory, as well as to develop practical recommendations for the implementation of innovative cluster development programs in the regional economy.
\end{abstract}

Key words: innovation, innovation activity, innovation cluster, competitiveness of the regional economy, regional economy.

Citation. Lapina M.S. Formation and Development of Innovative Clusters as a Tool for Innovative Activities of the Region. Vestnik Volgogradskogo gosudarstvennogo universiteta. Ekonomika [Journal of Volgograd State University. Economics], 2021, vol. 23, no. 2, pp. 42-56. (in Russian). DOI: https://doi.org/10.15688/ek.jvolsu.2021.2.4

\section{ФОРМИРОВАНИЕ И РАЗВИТИЕ ИННОВАЦИОННЫХ КЛАСТЕРОВ КАК ИНСТРУМЕНТА ИННОВАЦИОННОЙ ДЕЯТЕЛЬНОСТИ РЕГИОНА}

\author{
Марина Сергеевна Лапина \\ Волгоградский государственный университет, г. Волгоград, Российская Федерация
}

\footnotetext{
Аннотация. Актуальность необходимости проведения исследования обусловлена современной траекторией инновационного развития РФ. В статье особое внимание уделено аспекту анализа факторов, формирующих инновационный потенциал России на мезоуровне. Изучение зарубежного и отечественного опыта функционирования региональных инновационных кластеров позволило выявить основные тенденции, про$\hat{j}$ блемы развития и направления совершенствования инновационных кластеров как инструмента инновационной деятельности региона. В аналитической части исследования проведен анализ функционирования региональных инновационных кластеров (на примере европейских и азиатских стран). В ходе исследования было выявлено содействие модернизации экономики за счет инноваций и повышения конкурентоспособности промышленности. Зарубежный и отечественный опыт реализации стратегий регионального инновационного развития позволяет определить общие признаки распределения региональных факторов инноваций,
} 
преимущества, недостатки, перспективы формирования, реализации и совершенствования программ развития инновационных кластеров на мезоуровне. В статье определено положительное влияние государственного стимулирования и поддержки инновационной деятельности, наличия развитой инновационной инфраструктуры, а также сетевого взаимодействия между крупными корпорациями, малыми фирмами, научноисследовательскими институтами и государством на социально-экономическое развитие территорий. Результаты анализа могут служить основой для адаптации успешного зарубежного опыта формирования и развития инновационных кластеров в регионе в целях создания конкурентной инновационной среды территории, а также выработки практических рекомендаций по реализации программ инновационного кластерного развития в региональной экономике.

Ключевые слова: инновации, инновационная деятельность, инновационный кластер, конкурентоспособность экономики региона, региональная экономика.

Цитирование. Лапина М. С. Формирование и развитие инновационных кластеров как инструмента инновационной деятельности региона // Вестник Волгоградского государственного университета. Экономика. -2021. - Т. 23, № 2. - C. 42-56. - DOI: https://doi.org/10.15688/ek.jvolsu.2021.2.4

\section{Введение}

Ориентация национальной экономики РФ на инновационное развитие обусловливает создание, развитие и поддержку инновационных кластерных образований на макро- и мезоуровне.

Инновационные кластеры представляют собой наиболее передовую из всех форм развития объединений и являются наиболее эффективной платформой для реализации инноваций. Изучение инновационных кластеров сосредоточено главным образом на понятиях, характеристиках, классификациях инновационных кластеров, результатах исследований зарубежных ученых в области теории инновационных преимуществ кластера, теории инновационных систем, теории новых технологий и т. д. В настоящее время в исследованиях по инновационным кластерам остается много вопросов, которые необходимо изучить. Переход от фактора времени к изучению геопространственного фактора, в рамках которого региональные структуры и некоторые переменные в макроэкономических моделях должны быть охвачены количественной моделью, могут послужить основой исследования тенденций развития инновационных кластеров.

В настоящее время инновационные кластеры на макроуровне стали важным источником формирования своеобразных форм экономической организации и региональной конкурентоспособности в мировой экономике. На протяжении многих лет восточные страны шли по пути внедрения технологий, западные страны, в свою очередь, блокировали техно- логические обмены внутри страны по причине отсутствия собственного потенциала для самостоятельного исследования и разработки, а также в связи с недостаточным уровнем развития среды для научно-технического обмена. Тем не менее в большинстве развитых и развивающихся стран темпы инновационной деятельности находятся на этапе становления и формирования. Современные исследования в области экономики по-прежнему сосредоточены на изучении и практических предложениях, касающихся как собственно создания инновационных объединений, так и их нынешнего состояния, а также относительно роли правительств в их инновационной деятельности и того, каким образом местные органы власти могут содействовать созданию инновационных объединений. С течением времени роль правительства в формировании и развитии инновационных кластеров возросла. Результаты исследования организационных процессов и стратегий формирования и развития инновационных кластеров как инструмента инновационной деятельности региона могут служить основой для формирования кластерной инновационной политики региона.

\section{Материалы и результаты исследования}

В современной экономике ведущую роль играет инновационная деятельность, что является логическим завершением стадии индустриальной экономики и переходом к ее постиндустриальной фазе. Этот процесс неравномерен во времени и пространстве экономической деятельности отдельных стран и даже 
регионов страны, а процесс формирования траектории к инновационному будущему определяется кадровыми, научно-техническими, производственными, технологическими, финансовыми, организационными и другими особенностями отдельных территорий [Bekes, 2008]. Одна из таких составляющих - инновационная активность территории, которая определяет возможности реализации ее инновационного потенциала и характеризует, в свою очередь, степень эффективности инновационной деятельности.

Инновационная деятельность широко рассматривается как главный фактор экономического роста территории [Портер, 2006]. Оценка эффективности мер стимулирования инновационной активности, предлагаемая в теоретических работах, противоречива, чаще всего в силу произвольного выбора факторов, включенных в эмпирическую модель исследования. В статьях зарубежных ученых, в частности А. Джаффе и Дж. Лернера, рассматриваются различные факторы, стимулирующие инновационную активность регионов, в широком диапазоне - от уровня конкуренции на рынке до эффекта масштаба или распространения технологий.

Однако некоторые авторы, например К. Грасмик, настаивают на существовании обратной зависимости, в которой уровень развития региональной экономики, уровень доходов жителей, социальная дифференциация и стоимостная составляющая затрат на исследования и разработки определяют ее инновационную активность.

Споры о том, что приводит к региональному экономическому росту и значительному увеличению валового регионального продукта, еще не закончены: специализация, дифференциация секторов или инновационный компонент в контексте взаимосвязанных экономических платформ. Этому вопросу посвящены статьи И. Хасана, П. Вахтеля, М. Чжоу, С. Перцева.

Вклад малого бизнеса в развитие территорий также широко исследовался А. Арора и А. Гамбарделла. Отмечается отсталость малого бизнеса в инновационном развитии от среднего и крупного бизнеса: в целом $10,1 \%$ предприятий внедряют технологические инновации по экономике, а малые предприятия - только 5,1 \% [Федеральная служба ...]. Разрыв по доле инновационных товаров в общем объеме производства составил: $6,3 \%$ по экономике в целом и всего $1,48 \%$ - по малым предприятиям [Федеральная служба ...].

В связи с этим можно констатировать, что интегральный индекс инновационной активности в регионах в определенной степени соответствует величине валового регионального продукта, но взаимосвязь между этими показателями изучена недостаточно.

В работах О. Солвелла, Г. Линдквиста, К. Кетелса, Н.Н. Шиловой, Е.П. Киселица, С.А. Люфт были выполнены различные варианты кластеризации и выделены типы регионов с разным инновационным потенциалом. Однако зависимость между факторами, определяющими степень инновационного развития в каждом конкретном случае, мало изучена.

Все это затрудняет адекватную оценку параметров экономического воздействия на субъекты регионов и стимулирование инновационных факторов их развития и увеличения валового регионального продукта и предопределяет дальнейшую целесообразность исследований в этой области.

Для проведения анализа функционирования инновационных кластеров термин «кластер» автор определяет как «сконцентрированные по географическому признаку группы взаимосвязанных компаний, специализированных поставщиков, поставщиков услуг, фирм в соответствующих отраслях, а также связанных с их деятельностью организаций (например, университетов, агентств по стандартизации, а также торговых объединений) в определенных областях, конкурирующих, но вместе с тем, ведущих совместную работу» [Портер, 2003, c. 258].

Процесс формирования кластеров связан с использованием следующих механизмов:

- выделение финансовых ресурсов в виде беспроцентных ссуд (Швеция), прямого финансирования, доля которых иногда достигает 50 \% от общих вложений в разработку той или иной инновации (Россия, США, Франция);

- предоставление льготных условий для компаний и предприятий при налогообложении, в том числе исключение из налогооблагаемых сумм затрат на НИОКР и списание инвести- 
ций на НИОКР, льготное налогообложение университетов и научно-исследовательских институтов (Япония);

- гарантия защиты интеллектуальной собственности и авторских прав с точки зрения законодательства (во многих развитых странах);

- предоставление государством услуги патентного поверенного (Азербайджан, Армения, Белоруссия, Казахстан, Киргизия, Россия, Таджикистан и Туркменистан);

- страхование возможных рисков от проектов и разработок;

- привлечение иностранных «мозгов», то есть высококвалифицированных и имеющих релевантный опыт профессионалов, а также содействие в виде упрощения их переезда [Report of the ...; Audretsch et al., 1996; Jaffe, 1993; Sakhariyeva, 2013].

Обобщая ряд определений, определим инновационный кластер отрасли как группу активно вовлеченных и активных корпораций, созданных и действующих на определенной территории. Как правило, в рамках функционирования кластеров происходит исследование инновационных технологий и услуг для улучшения транспортных возможностей, качества обслуживания клиентов, производственных процессов и любых других вопросов, связанных с интеллектуальной мобильностью.

Инициирование инноваций за пределами установленных процессов на определенной территории, отраслей и даже корпоративных границ возможно преодолеть при поддержке команды внутри специализированного центра инноваций или исследований и разработок. Совместная инициатива участников кластера направлена на обмен инновационными идеями, создание общих команд и софинансирование проектов, связанных с инновациями, с обменом результатами в итоге.

Одной из важнейших характеристик инновационных кластеров является их географическая концентрация, то есть большое количество смежных отраслей сосредоточено в определенной географической зоне. Благодаря географической близости, самоусиливающийся механизм конкуренции внутри инновационного кластера формирует механизм естественного отбора для «выживания наибо- лее приспособленных» внутри кластера, стимулируя инновации и выделение предприятий. В инновационном кластере концентрируется большое количество компаний для ведения жесткой рыночной конкуренции и различных форм сотрудничества. Например, совместная разработка новых продуктов, открытие новых рынков и создание производственной цепочки поставок, тем самым формирующие механизм совместной конкуренции, сочетающий конкуренцию и сотрудничество. Основополагающая черта этого механизма сотрудничества - взаимопомощь и коллективные действия. Посредством такого сотрудничества малые и средние предприятия могут достичь эффективного сетевого взаимодействия и сотрудничества в области обучения, финансов, разработки технологий, дизайна продукции, маркетинга, экспорта, распределения и т. д., чтобы преодолеть недостатки своей внутренней экономии за счет масштаба, что позволит соревноваться с устойчивыми конкурентами. В инновационных кластерах, когда многие отдельные малые предприятия, неконкурентоспособные по сравнению с крупными предприятиями, подключаются к развитой региональной сети, их конкурентоспособность перестает быть конкурентоспособностью отдельных предприятий, а является своего рода новой конкурентоспособностью, совершенно новой, более выгодной, чем конкурентоспособность всех отдельных предприятий. Кластер формирует множество малых и средних предприятий, которые не имеют возможности выжить на рынке по отдельности, но, участвуя в кластере, они не только выживают, но и повышают общую конкурентоспособность кластера. Кластеры не только способствуют повышению производительности, но и способствуют продвижению корпоративных инноваций, воплощенных во многих аспектах, таких как концепция, управление, технология, система и окружающая среда.

Инновационные кластеры обладают характеристиками географической агломерации. Поэтому отраслевые предприятия и поддерживающие их предприятия, а также соответствующие вспомогательные учреждения, такие как органы местного самоуправления, отраслевые ассоциации, финансовые департаменты, образовательные и учебные заведе- 
ния, образуют гибкий производственный комплекс. Это составляет основу конкурентоспособности региона. Кроме того, формирование кластеров побуждает правительство инвестировать в соответствующие общественные объекты, такие как образование, обучение, тестирование и идентификация кластеров; кроме того, создание этих объектов, очевидно, способствовало развитию предприятий в кластере. Совместное использование общественных благ делает ресурсы более эффективными при функционировании инновационных кластеров. Успех кластеров отрасли и продукты, на которые они опираются при международной интеграции, способствуют формированию всемирно известного регионального бренда. «Бренд местоположения» означает, что местоположение отрасли является символом бренда, такого как французская парфюмерия, итальянская мода и швейцарские часы. Стоит отметить, что отдельной компании требуются огромные капитальные вложения для создания собственного бренда. Однако с помощью кластера, общей силы предприятий в нем, увеличения рекламы легко сформировать «бренд местоположения». По сравнению с единым корпоративным брендом локальный бренд является более ярким и прямым. Это обогащение и усовершенствование многих корпоративных брендов. Он оказывает более широкое и непрерывное влияние на бренд. Это ценный нематериальный актив. Такой региональный бренд создается на единой производственной базе предприятий, а после его создания может использоваться всеми предприятиями региона. Следовательно, у региональных брендов есть и внешние эффекты. Этот эффект регионального брендинга способствует не только изучению внутренних и внешних рынков и определению соответствующих цен реализации, но также повышению имиджа всего региона, создавая благоприятные условия для привлечения инвестиций и будущего развития. Совместное использование региональных брендов значительно увеличивает сравнительные конкурентные преимущества предприятий кластера.

В последние годы инновационные кластеры в качестве модели для содействия региональному экономическому развитию, наряду с экономической глобализацией, ста- ли привлекательной мировой моделью регионального экономического развития и важной организационной формой экономического развития, что заслуживает широкого внимания соответствующих международных организаций, многих стран и местных органов власти.

С усилением развития региональной экономики инновационные кластеры стали важной организационной формой экономики различных территорий, при этом статистические исследования и анализ их деятельности также заслуживают особого внимания. В настоящее время нет единого стандарта для статистических исследований и комплексной оценки инновационных кластеров на различных уровнях. Однако научная и объективная оценка качества инновационных кластеров, наблюдение за их статусом в условиях жесткой рыночной конкуренции, изучение условий повышения конкурентоспособности на рынке являются основанием для разработки научно обоснованной и комплексной системы оценочных индексов и индикаторов, отражающей характеристики кластера с разных точек зрения.

Положительный опыт ряда Европейских стран (Венгрия, Румыния, Словения) свидетельствует о решающей роли инновационного развития в повышении конкурентоспособности экономики на национальном и региональном уровне.

К основным направлениям реализации программ развития инновационных кластеров в Европе следует отнести:

- повышение конкурентоспособности промышленности;

- содействие сотрудничеству в обмене инновационными идеями и ноу-хау в секторе НИОКР;

- содействие сотрудничеству между академическим и деловым секторами;

- разработка новых финансовых инструментов из государственных и частных источников;

- развитие инновационной экосистемы на мезоуровне;

- определение потенциальных возможностей сотрудничества в области НИОКР между представителями делового сектора и университетами; 
- совместное управление более крупными инновационными проектами с возможностью консультирования и обучения;

- осуществление широкого спектра мероприятий в области финансирования из грантов и других видов финансирования;

- создание ноу-хау среди членов кластера.

Модель функционирования европейских кластеров включает 4 основных блока:

I. Управление:

1) ассоциация компаний-членов;

2) единая стабильная команда лидеров, выбранная каждым участником кластера;

3) совместное принятие решений по проектам НИОКР.

II. Механизмы финансирования:

1) государственное финансирование;

2) прямые инвестиции участников;

3) гранты / программы, финансируемые государством.

III. Сервисы:

1) управление крупными инновационными проектами, отчетность и управление;

2) консультирование и управление финансами и инвестициями;

3) юридическая поддержка;

4) коучинг и наставничество, ускорение существующих инновационных идей;

5) поощрение пилотных бизнес-проектов и внедрение;

6) сотрудничество с университетами;

7) размещение объединенной проектной команды;

8) и др.

IV. Операционные платформы:

1) дизайн-мышление - процесс сотрудничества, который тщательно изучает потребности пользователей, рассматривает множество вариантов, использует быстрые прототипы для уточнения выбранных направлений на основе новых идей;

2) итеративный, поэтапный процесс разработки любого продукта и управления любой работой, в которой решения развиваются в результате сотрудничества между самоорганизующимися и кросс-функциональными командами, стремящимися обеспечить максимальную ценность для бизнеса в кратчайшие сроки;

3) систематическое развитие сетей отдельных лиц, заинтересованных сторон и пред- приятий для совместного создания ценности с помощью платформ взаимодействия;

4) открытые инновации - «открытие» инновационной воронки для выхода за рамки традиционных входов развития, таких как внутреннее развитие, и выходов, таких как текущий рынок;

5) совместное инвестирование - ресурсы и средства вложены согласно заранее согласованным правилам и принципам. Право собственности на результаты каждого проекта, которым будет управлять кластер, должно быть ясно определено до того, как начнется какая-либо совместная инициатива.

Анализ реализации программ развития инновационных кластеров в странах Азии (Китай, Корея) позволил выделить преимущества и недостатки влияния инновационных кластерных образований на мезоуровне.

К преимуществам относятся:

1. Развитие сфер деятельности, поддерживающих профессионализм, надежность, высокий коэффициент использования ресурсов на территории.

2. Привлечение инвестиций, расширение производства, кооперация между предприятиями, государством и т. д.

3. Развитие и совершенствование политики государственной поддержки предприятий инновационного кластера.

4. Развитие конкуренции между предприятиями, которая будет более целенаправленной и стандартизированной, а также приведет к сокращению внутреннего потребления в отрасли.

5. Технологические исследования и инновационные проекты способны сделать быстрый прорыв и осуществить коммерческую трансформацию через инновационные союзы.

К недостаткам относятся:

1. Отсталым предприятиям легче подготовиться к ликвидации, присоединившись к инновационным кластерам.

2. Руководство предприятия подвержено влиянию государства и конкурентов.

3. Сокращение цикла прибыли от инноваций предприятия.

4. Частый отток основного персонала.

5. Конкуренция между предприятиями трансформируется от доминирующей к рецессивной, что/и может привести к ухудшению конкурентной ситуации. 
Таким образом, к ключевым направлениям в рамках реализации инновационной кластерной политики в Азии относятся:

- значительное повышение качества условий научно-исследовательской базы и уровня обслуживания, значительное расширение возможностей науки и техники по стимулированию перехода к региональной экономике;

- достижение прогресса в создании научно-технической базы инновационной деятельности, а также в формировании кадров по вопросам промышленной инновационной деятельности, возглавляемой предприятиями;

- сосредоточение внимания на таких темах, как охрана окружающей среды, освоение природных ресурсов и модернизация производственных мощностей, борьба с опустыниванием, сохранение и восстановление почв и экосистем, рациональное использование водных ресурсов, охрана биологического разнообразия, борьба со стихийными бедствиями в горных районах;

- модернизация промышленности по производству оборудования, поддержка научнотехнических инноваций в ключевых областях;

- создание системы мониторинга и комплексной оценки экологической безопасности территорий, геопоисковая и комплексная система борьбы с геологическими бедствиями, совершенствование технологий комплексного использования ресурсов соляных озер и горных районов, укрепление исследований и разработок в области водных ресурсов, содействие научно-исследовательским работам, построение высокогорных агроскотоводческих комплексов, в целях устойчивого экономического и социального развития территорий.

Для достижения поставленных целей правительствами азиатских стран определены следующие задачи:

- ориентация на рыночный спрос, повышение регионального инновационного потенциала, создание основных научно-технических работ и проектов с региональной спецификой, высокотехнологичное инвестирование в развитие науки и техники, координация развития, создание региональной системы инноваций и технологических инноваций в качестве новой модели, способствующей глубокой интеграции научно-технических инноваций и социально- экономического развития, обеспечение надежной научно-технической поддержки;

- комплексное планирование;

- рыночная ориентация;

- прорыв технологий, внедрение технологических инноваций и демонстрационного применения, содействие комплексному развитию инфраструктуры, экологии, особых отраслей промышленности и социальной сферы в выбранных приоритетных регионах;

- долгосрочный подход к перспективным исследованиям.

Захват передовых точек инновационного развития в соответствующих областях, разработка различных научно-технических и инновационных планов возможны при реализации следующих мероприятий в рамках реализации кластерной инновационной политики:

1. Расширение научно-технического сотрудничества с ориентацией на потребности экономического и социального развития регионов, непрерывное совершенствование научно-технической базы, поддержка развития ключевых лабораторий, инженерных лабораторий, инженерных научно-исследовательских центров и технологических центров предприятий. Стимулирование обмена научно-исследовательскими институтами, высшими учебными заведениями и научно-исследовательскими ресурсами, укрепление основных научных объектов, научно-исследовательских инструментов. Поощрение научно-исследовательских институтов, высших учебных заведений и предприятий к созданию научно-исследовательских платформ, интеграции научно-технических и инновационных ресурсов и укреплению потенциала предприятий в области технологических инноваций.

2. Содействие превращению научно-технических достижений в основные научно-технические потребности, такие как модернизация традиционной промышленности, развитие стратегических и новых отраслей промышленности, экологическое строительство и жилищное строительство. Направление различных инновационных элементов на предприятия в целях повышения их способности к самостоятельной инновационной деятельности. Создание платформ для передачи научно-технических достижений, осуществления 1000 проектов по конверсии научно-технических достижений. 
3. Создание региональных инновационных систем и инновационных отраслевых объединений, настаивающих на совмещении государственного управления и рыночной конфигурации, интеграции инновационных ресурсов, объединения инновационных элементов, укрепления инновационных функций, основания региональных инновационных систем с ярко выраженными особенностями и преимуществами.

4. Активизация усилия по развитию талантов, чтобы в полной мере использовать научно-исследовательские институты и высшие учебные заведения, научно-исследовательские ресурсы, активизировать усилия по развитию талантов всех видов, энергично осуществлять такие специальные программы подготовки кадров, сосредоточить усилия на приоритетных областях, срочно недостающих кадрах и построить высокогорные районы, активно поощрять межрегиональный обмен талантами, поощрять и привлекать различные категории специалистов к освоению территорий на основе обмена сотрудниками, исследовательской подготовки, участия в международных научных обменах и т. д.

5. Оптимизация институциональных механизмов инновационной деятельности в целях поощрения эксперимента по реформированию системы управления научно-технической инновацией с учетом региональных условий и изучения механизмов комплексного распределения научно-технических ресурсов на межправительственном уровне. Исходя из интенсивного преимущества военных и промышленных предприятий в регионе, изучение возможности создания системы оборонно-технических инноваций, сочетающих военные и гражданские действия.

6. Использование интеллектуального превосходства специалистов научно-технических отделов академии наук, научно-исследовательских институтов и других учебных заведений, активное проведение мероприятий по стратегическому консультированию и научнотехническому обслуживанию в области индустриализации, информатизации, урбанизации и модернизации сельского хозяйства на мезоуровне по таким важным вопросам, как индустриализация, информатизация, урбанизация и модернизация сельского хозяйства. В соот- ветствии с территориальными реальными потребностями проводятся тематические исследования и консультации по таким важным вопросам, как региональное промышленное развитие, научно-техническое новаторство, развитие людских ресурсов, охрана окружающей среды и соответствующее целевое планирование, с целью обеспечить основу для принятия научных решений соответствующими министерствами и органами местного самоуправления.

7. Интеграция основных технологий в области охраны окружающей среды. Комплексная борьба с опустыниванием сосредоточена на бассейне внутренних рек, сохранении почв в горных районах и водных ресурсов, управлении водными ресурсами и земельными ресурсами, охране окружающей среды, крупных промышленных зон, охране экологии степей и т. д.

8. Комплексная оценка состояния строительства, внедрение ключевых технологий, интегрированные инновации, разработка моделей прикладного распространения, демонстрация образцов и предоставление системных инженерных решений для рационального природопользования в засушливых и полузасушливых районах.

9. Активизация усилий по изучению долгосрочных механизмов стимулирования роста инвестиций в науку и технику и укрепление гарантии государственных инвестиций в инновации в области науки и техники на основе полного применения имеющихся ресурсов при использовании национальных средств для поддержки приоритетных задач и проектов в рамках стратегических действий.

Таким образом, исходя из анализа деятельности инновационных кластеров в Азии, для реализации стратегии инновационного развития необходимо следовать основным принципам и требованиям для дальнейшего повышения эффективности распределения региональных факторов инноваций.

При обобщении опыта европейских и азиатских стран выявлены три аспекта, в которых сосредоточено влияние инновационных кластеров на экономическую ситуацию в стране:

1. Кластеры могут создать на предприятиях хорошую атмосферу для инноваций. Кла- 
стеры являются очагом развития у предприятий возможностей для обучения и инноваций. Близкие друг к другу компании будут находиться под невидимым давлением конкуренции, вынуждающей компании продолжать внедрять технологические инновации и инновации в области организационного управления. Из-за конкурентного давления и проблем предприятиям в кластере необходимо постоянно вводить новшества и улучшать дизайн, разработку, упаковку, технологии и управление продукции, чтобы адаптироваться к быстро меняющимся потребностям рынка. Инновации в области знаний компании могут легко распространиться на другие компании в регионе, потому что эти компании могут быстро осваивать новые знания и технологии посредством визитов на места и регулярного личного общения. В промышленных кластерах изза географической близости тесное сотрудничество между компаниями позволяет вести личные дела. Это будет способствовать распространению различных новых идей, новых концепций, новых технологий и новых знаний, тем самым создавая побочный эффект знаний и создавая «экономику обучения» (Learning Economies) для расширения исследовательских и инновационных возможностей компании.

2. Кластеры способствуют передаче и распространению знаний и технологий. Между промышленными кластерами и распространением знаний и технологий существуют взаимоусиливающие и самоподкрепляющиеся отношения. В новую экономическую эпоху промышленная структура уже не такая простая, как в эпоху индустриальной экономики. Все слои общества просто сгруппированы вместе, но взаимосвязанные и узкоспециализированные отрасли регулярно объединяются в одной области, образуя уникальные промышленные кластеры. Благодаря пространственной близости и общему промышленному культурному фону внутри кластера можно не только усилить распространение явных знаний, но, что более важно, увеличить неявные знания, быстрый поток которых может способствовать дальнейшему развитию явных знаний. Из-за большого количества аналогичных предприятий в промышленном кластере давление конкуренции стимулирует технологические инновации предприятий, а также за- ставляет сотрудников соперничать друг с другом и продолжать учиться; близость предприятий открывает возможности для визитов на места и личного общения. Эта обучающаяся и конкурентная региональная среда содействует технологическим инновациям предприятий; ведущие предприятия в кластере будут руководить направлением развития промышленных технологий. Как только определенная базовая технология достигнет инновационного прорыва, предприятия различных профессиональных сегментов в области кластера вскоре будут сотрудничать в области инноваций, поддерживать друг друга и участвовать вместе. Это становится проявлением сетевых инновационных моделей. Распространение знаний и технологий в промышленных кластерах происходит значительно быстрее, чем на некластеризованных предприятиях.

3. Кластеры могут снизить стоимость корпоративных инноваций. Благодаря близкому географическому положению возможны частые обмены между собой, что дает предприятиям больше возможностей для обучения инновациям. В частности, обмен неявными знаниями может стимулировать появление нового мышления и новых методов. В силу развития «экономики знаний» для специализированных малых предприятий в кластере становится легко и недорого изучать новые технологии. В то же время механизм конкуренции и сотрудничества, основанный на взаимном доверии, также будет способствовать укреплению сотрудничества в области технологических инноваций между предприятиями, тем самым снижая стоимость разработки новых продуктов и технологических инноваций.

Кластеры также оказывают важное влияние на появление новых предприятий и их рост. С одной стороны, хорошая инновационная атмосфера, жесткая конкурентная среда и полноценная региональная система поддержки дают кластеру конкурентное преимущество в привлечении новых предприятий; с другой стороны, географическая концентрация и хорошая внешняя среда не только стимулируют появление новых игроков отрасли, но также способствуют росту и расширению масштабов существующих предприятий. После формирования промышленных класте- 
ров привлеченные внешние предприятия не только будут укоренены на региональном уровне, но также появится много новых предприятий, которые будут развиваться и расти на мезоуровне.

За годы осуществления стратегии экономического и социального развития территорий РФ произошли значительные социальноэкономические изменения, заметно улучшились условия жизни городского и сельского населения, достигнуты заметные успехи в развитии инфраструктуры, экологии, особых отраслей промышленности, социальной сферы и т. д. Однако общий уровень социальной продуктивности в некоторых регионах по-прежнему является низким и по-прежнему сохраняются диспропорции и неустойчивость в области развития, а также насущная необходимость ускорения темпов модернизации промышленной структуры и осуществления социально-экономических преобразований. Научно-техническое новаторство является стратегической опорой для повышения производительности общества и совокупного государственного потенциала, а также главной движущей силой в экономике. Всемерное стимулирование научно-технического новаторства, изучение эффективных путей содействия региональному развитию стали важными задачами осуществления стратегии развития на мезоуровне.

Согласно Global Innovation Index (GII 2020), Россия находится на 47-м месте из 131 страны по уровню инновационного развития в контексте глобальной кластеризации, поднявшись с 2015 г. всего на 2 пункта. РФ имеет низкие показатели кластерного развития по сравнению со странами-лидерами: 95-е место в мировом рейтинге, незначительный уровень кластерной концентрации - 0,3 и интегральной оценки по GII - 3,4 из 7 (максимальная рейтинговая оценка) (табл. 1).

Позиция РФ объясняется тем, что $s$ инновационных кластеров находятся на начальном этапе становления и развития, так как созданы после 2012 года.

В Российский Федерации начиная с 2012 г. можно выделить 2 основные тенденции кластерной политики государства, которые определяют специфику кластерного развития и форм кластеризации территории:

1. Программная поддержка ИТК - инновационных территориальных кластерных образований (Минэкономразвития России) (см. рис. 1).

2. Собственная программная поддержка (Минпромторг).

Минпромторг России осуществляет собственную программную поддержку промышленных кластеров.

Программа поддержки ИТК, разработанная с учетом лучших международных практик кластерного развития (программа поддержки ведущих кластеров Германии Spitzencluster Wettbewerb; программа поддержки полюсов конкурентоспособности Франции Pôles de Compétitivité), реализуется на территории России Минэкономразвития РФ с 2012 года. Основной целью данной программы является укрепление кооперации между предприятиями, научно-образовательными организациями - участниками кластерных образований, а также повышение научно-технического и производственного потенциала наиболее инновационно-активных территорий РФ.

Показатели уровня кластеризации в 2018-2020 гг.

\begin{tabular}{|c|c|c|c|c|c|c|c|c|}
\hline Страна & $\begin{array}{c}\text { Интегральная } \\
\text { оценка по GII } \\
2018 \text { г. }\end{array}$ & № & Страна & $\begin{array}{c}\text { Интеграль- } \\
\text { ная оценка } \\
\text { по GII } 2019 \text { г. }\end{array}$ & № & Страна & $\begin{array}{c}\text { Интегральная } \\
\text { оценка } \\
\text { по GII } 2020 \text { г. }\end{array}$ & $\begin{array}{l}\text { Кластерная } \\
\text { концентра- } \\
\text { ция 2020 г. }\end{array}$ \\
\hline США & 5,7 & 1 & Италия & 5,5 & 1 & США & 5,5 & 1 \\
\hline Швейцария & 5,5 & 2 & Германия & 5,4 & 2 & Китай & 5,4 & 0,99 \\
\hline Нидерланды & 5,4 & 3 & Швейцария & 5,3 & 3 & Швейцария & 5,3 & 0,98 \\
\hline Китай & 5,4 & 4 & Китай & 5,3 & 4 & Германия & 5,3 & 0,98 \\
\hline Япония & 5,3 & 5 & Нидерланды & 5,2 & 5 & $\begin{array}{l}\text { Велико- } \\
\text { британия }\end{array}$ & 5,3 & 0,97 \\
\hline Россия & 3,5 & 101 & Россия & 3,4 & 95 & Россия & 3,4 & 0,3 \\
\hline
\end{tabular}

Примечание. Источник: [Global Innovation Index ...]. 

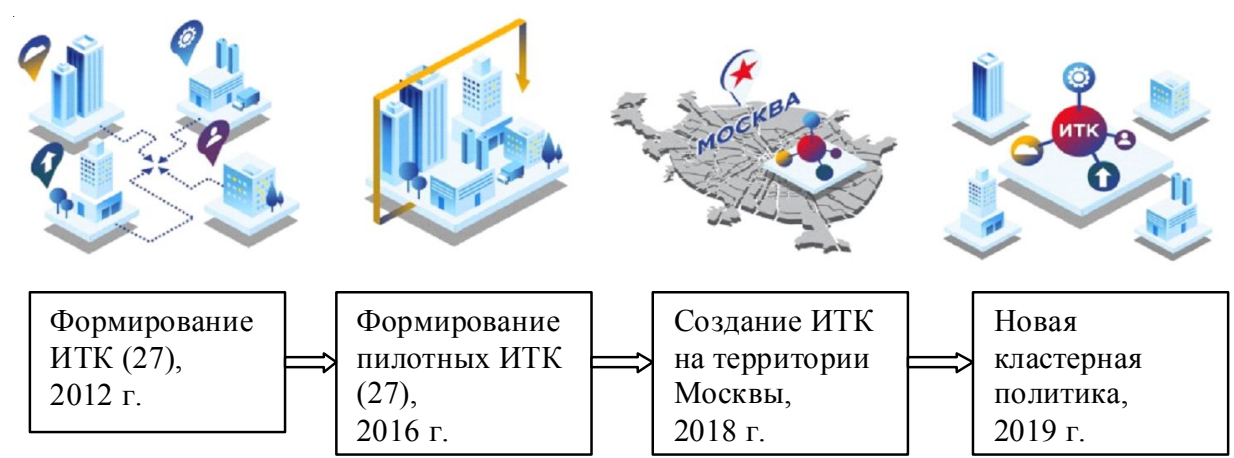

Рис. 1. Динамика создания ИТК в РФ

Примечание. Источник: [Российская кластерная обсерватория ...].

Реализация данной программы направлена на преодоление разрыва между наукой и производством путем оказания поддержки передовым кластерам в наукоемких секторах и регионам их базирования, а также развитие синергии и софинансирования совместных исследовательских проектов участников кластеров, коммерциализации их результатов.

Данные программы предполагали проведение конкурсов с целью отбора лучших кластерных проектов, реализация которых субсидировалась в течение 5 лет из государственного бюджета. Например, на территории Германии в настоящее время функционируют 15 кластеров, которые на мировом уровне признаны ведущими, а во Франции 70 кластерных проектов являются высококонкурентоспособными.

В России также проводился конкурсный отбор пилотных ИТК. Из 94 поданных на конкурс заявок было отобрано 25 (в 2015 г. - 27, в 2018 г. - 25, в 2020 г. - 31) кластерных проектов (см. табл. 2-3), которые реализуются в настоящее время на территориях с высоким уровнем инновационной активности, в частности, в регионах, признанных особыми экономическими зонами (ОЭЗ), закрытыми территориальными образованиями (ЗАТО), территориями опережающего развития (ТОР), где функционируют наукограды.

ИТК функционируют в таких основных отраслях экономики, как биотехнология, информационно-коммуникационные технологии, медицинская промышленность, нефтехимия, судостроение, электроника, создание аэрокосмических аппаратов, ядерных и радиационных технологий.
На основе анализа вышеприведенных расчетов, следует, что:

1. ИТК в РФ является эффективным, если: в рамках оценки производительности труда в субъектах хозяйствования - участников кластерных образований на 1 работника приходится не меньше 6,67 млн руб.; на 1 участника кластерного образования приходится не меньше 728 млн руб. в совокупном объеме налоговых поступлений; налоговая нагрузка на 1 его участника не превышает 1 тыс. руб. на 1 доллар инвестиционных вложений.

2. ИТК в РФ является неэффективным, если: в рамках оценки производительности труда в субъектах хозяйствования - участников кластерных образований на 1 работника приходится менее 1,65 млн руб.; на 1 участника кластерного образования приходится меньше 323,9 млн руб. в совокупном объеме налоговых поступлений.

К лидирующим отраслям в РФ, в которых активно формируются кластеры, следует отнести: информационные технологии, туризм (Кавказ), химия и нефтехимия (Поволжский, Западно-Сибирский, Восточно-Сибирский, Дальневосточный, Северо-Западный, Каспийский кластеры), нанотехнологии, фармацевтика и медицина. 28 августа 2012 г. поручением Председателя Правительства Российской Федерации № ДМП85060 утвержден перечень инновационных региональных кластеров. В перечень включены 25 региональных кластеров, определенных с помощью конкурсного отбора, осуществленного в рамках деятельности Рабочей группы по развитию частногосударственного партнерства в инновационной сфере при Правительственной комиссии по высоким технологиям и инновациям, в соответствии с 


\section{Экономическое состояние инновационных территориальных кластеров} по состоянию на 2020 г.

\begin{tabular}{|c|c|c|c|c|}
\hline $\begin{array}{c}\text { Уровень } \\
\text { эффективности }\end{array}$ & $\begin{array}{c}\text { Производ. труда, } \\
\text { млн руб. на чел. }\end{array}$ & $\begin{array}{c}\text { Величина налог. поступл. } \\
\text { на 1 участника, млн руб. }\end{array}$ & $\begin{array}{c}\text { Кол-во совместн. } \\
\text { проект. на 1 участника }\end{array}$ & $\begin{array}{c}\text { Налог. нагрузка, } \\
\text { млн руб. }\end{array}$ \\
\hline Высокий уровень & 6,671 & 728 & 0,3 & 822,4 \\
\hline Средний уровень & 2,505 & 556,7 & 0,22 & 960 \\
\hline Низкий уровень & 1,65 & 323,9 & 13 & 1064,8 \\
\hline
\end{tabular}

Примечание. Источник: [Реализация ...].

Таблица 3

Инновационные территориальные кластеры по уровню эффективности на 2020 г.

\begin{tabular}{|c|c|c|}
\hline № & Кластер & $\begin{array}{c}\text { Уровень } \\
\text { эффективности }\end{array}$ \\
\hline 1 & ИТК «Фотоника», Пермский край & \multirow{4}{*}{ Высокий уровень } \\
\hline 2 & ИТК ядерно-физических нанотехнологий, г. Дубна & \\
\hline 3 & Индустриальный ИТК в сфере нефтехимии и автомобилестроения, г. Нижний Новгород & \\
\hline 4 & ИТК Новые материалы, лазерные и радиационные технологии, г. Троицк & \\
\hline 1 & Кластер фармацевтики, биотехнологий и биомедицины, Калужский регион & \multirow{9}{*}{ Средний уровень } \\
\hline 2 & $\begin{array}{l}\text { Консорциум «Научно-образовательно-производственный кластер “Ульяновск-Авиа”», } \\
\text { Ульяновский регион }\end{array}$ & \\
\hline 3 & Ядерно-инновационный кластер, г. Димитровград, Ульяновский регион & \\
\hline 4 & $\begin{array}{l}\text { Промышленный кластер станкостроения и станкоинструментальной промышленности } \\
\text { «Липецкмаш» }\end{array}$ & \\
\hline 5 & Электротехнический кластер, Псковский регион & \\
\hline 6 & Биофармацевтический кластер, Алтай & \\
\hline 7 & Судостроительный ИТК, Архангельский регион & \\
\hline 8 & Аэрокосмический ИТК, Самарский регион & \\
\hline 9 & Биотехнологический ИТК «Пущино», Московский регион & \\
\hline 1 & Камский ИТК, Республика Татарстан & \multirow{18}{*}{ Низкий уровень } \\
\hline 2 & НПК «Сибирский наукополис», Новосибирский регион & \\
\hline 3 & Нефтехимический ИТК, Республика Башкортостан & \\
\hline 4 & Машиностроительный кластер Удмуртской Республики & \\
\hline 5 & $\begin{array}{l}\text { Кластер медицинской, фармацевтической промышленности, радиационных техноло- } \\
\text { гий, г. Санкт-Петербург }\end{array}$ & \\
\hline 6 & ИТК «Зеленоград», г. Москва & \\
\hline 7 & $\begin{array}{l}\text { Энергоэффективная светотехника и интеллектуальные системы управления освещени- } \\
\text { ем, Республика Мордовия }\end{array}$ & \\
\hline 8 & Комплексная переработка угля и техногенных отходов, Кемеровский регион & \\
\hline 9 & ИТК «Технополис “Новый Звездный”», Пермский край & \\
\hline 10 & ИТК «Физтех XXI», г. Химки, Московский регион & \\
\hline 11 & Кластер инновационных технологий ЗАТО, Красноярский край & \\
\hline 12 & $\begin{array}{l}\text { Развитие информационных технологий, радиоэлектроники, приборостроения, средств } \\
\text { связи и инфотелекоммуникаций, г. Санкт-Петербург }\end{array}$ & \\
\hline 13 & ИТК «Титановый кластер», Свердловский регион & \\
\hline 14 & $\begin{array}{l}\text { ИТК «Фармацевтика, медицинская техника и информационные технологии», Томский } \\
\text { регион }\end{array}$ & \\
\hline 15 & ИТК авиастроения и судостроения, Хабаровский край & \\
\hline 16 & $\begin{array}{l}\text { Кластер производителей нефтегазового и химического оборудования, Воронежский ре- } \\
\text { гион }\end{array}$ & \\
\hline 17 & Кластер машиностроения и приборостроения, Республика Бурятия & \\
\hline 18 & Кластер метровагоностроения, Московский и Тверской регион & \\
\hline
\end{tabular}

Примечание. Источник: [Реализация ....].

поручением Президента Российской Федерации по итогам заседания президиума Государственного совета Российской Федерации от 11 ноября 2011 г., а также решения Правительственной комиссии по высоким технологиям и инновациям от 30 января 2012 г. [Реализация ....].
Немаловажную роль при оценке эффективности реализации инновационных проектов в регионе имеет среда формирования и развития инновационных кластеров, которая, по мнению автора, представляет собой взаимосвязь трех компонентов - факторов развития (см. рис. 2). 


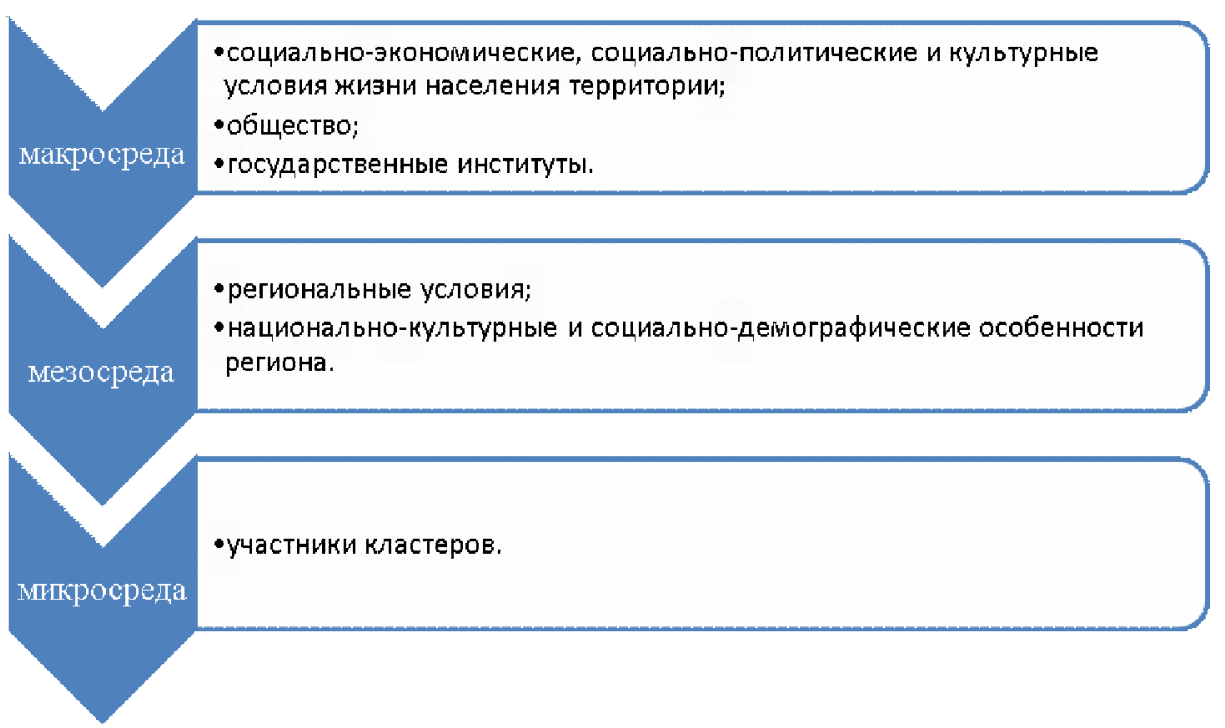

Рис. 2. Среда формирования и развития инновационных кластеров

Примечание. Составлено автором.

В перспективе инновационное развитие регионов РФ должно сопровождаться развитием высокотехнологичных производств, основанных на новых передовых технологиях. Конкурентным преимуществом регионов является наличие глубоких технологических традиций, развитие научно-образовательного комплекса, способного обеспечить разработку и внедрение современных технологий мирового уровня на действующих и новых предприятиях региона.

Для реализации данного направления необходимо провести ряд мероприятий:

1. Анализ инновационной активности промышленных предприятий в области на основании мониторинга, проводимого с периодичностью в один год.

2. Формированиекластеров инновационной активности промышленных предприятий, работающих в ключевых технологических секторах.

3. Формирование пакета наиболее перспективных инновационных проектов в каждом кластере.

4. Анализ проблем, приводящих к низкой инновационной активности промышленных предприятий региона.

5. Разработка моделей и методов, необходимых для повышения эффективности управления инновационным потенциалом промышленных предприятий региона.

Основные задачи направления формирования и развития инновационных класте- ров в социально-экономическом развитии территории:

1. Осуществление поддержки перспективных инновационных проектов в каждом кластере путем (поиска возможных инвесторов как внутри страны, так и за рубежом, мер государственной поддержки как на региональном, так и на федеральном уровнях).

2. Организация инновационного аудита в регионе.

3. Обеспечение постоянного независимого мониторинга инновационного развития в регионе.

4. Содействие процессу передачи технологий между отраслями промышленности и исследовательскими институтами в регионе.

Применение государственной поддержки для реализации всех вышепредставленных направлений следует проводить на комплексной основе, что, в свою очередь, будет усиливать синергетический эффект кластеров для национальной и региональной экономики.

Системообразующие элементы региональной инновационной инфраструктуры должны включать: государственные исследовательские центры, отраслевые институты, университеты, крупные научно-производственные предприятия, технопарки и бизнес-инкубаторы. Элементами системы, отвечающими за производство научно-технологического продукта и его продвижение на рынке, становятся инжиниринговые фирмы. 
Совершенствование региональной инновационной системы на мезоуровне может быть достигнуто посредством:

- активизации инновационной деятельности;

- национального размещения научно-технических ресурсов;

- инновационной эффективности;

- создания нескольких влиятельных инновационных промышленных кластеров и научно-исследовательских баз;

- создания группы ведущих предприятий, обладающих основными технологиями, автономными брендами, имеющими важное влияние в промышленности.

\section{Заключение}

Таким образом, проведенные исследования позволили обосновать наличие объективно существующей зависимости между показателями уровня инновационного развития региона и показателями кластерного развития территорий, а также выявить приоритетные факторы регионального развития в различных ситуациях в зависимости от степени их инновационного развития.

К сожалению, довольно часто обширные количественные показатели не в полной мере отражают эффект от инвестирования в инновационное развитие.

Таким образом, формирование и развитие региональных инновационных кластеров является эффективным механизмом привлечения инвестиций (как внутренних, так и иностранных), что способствует внешнеэкономической интеграции, которая, в свою очередь, позволяет значительно повысить уровень национальной и региональной технологической базы, увеличить скорость и улучшить качество экономического роста за счет повышения международной конкурентоспособности предприятий, входящих в состав кластера, а также их продукции.

Инновации как неотъемлемая черта предпринимательства в российских реалиях еще не получили полного развития. Это связано с имеющимися серьезными недостатками в существующих экономических механизмах, в первую очередь в тех, которые направлены на стимулирование и обес- печение условий для развития инновационной деятельности из-за единого подхода ко всем регионам без учета степени их реального инновационного развития. В дальнейшем проведенное исследование и рейтинг факторов позволят разработать индивидуальные схемы инновационного развития для каждого из четырех кластеров регионов в зависимости от степени их инновационного развития. Это позволит получить максимальную отдачу от вложенных средств и, в частности, самый высокий уровень валового внутреннего продукта, что особенно важно в современных условиях, поскольку именно инновационная модель развития в современной экономике называется приоритетной и даже единственной возможностью для закрепления позиций в условиях истощения природных ресурсов и усиления международной конкуренции.

Полученные результаты позволили авторам сформировать направления дальнейших исследований. Во-первых, необходимо разработать конкретные схемы инновационного развития каждого региона в зависимости от кластера, в который он входит, с учетом выявленного рейтинга факторов инновационного развития, определяющих уровень валового внутреннего продукта в каждом конкретном кластере.

Во-вторых, для каждого региона должны быть разработаны рекомендации, регламентирующие соблюдение определенных соотношений значений определяющих факторов (увеличение количества инновационно-активных предприятий, объем внутренних затрат на исследования, использование передовых производственных технологий и т. д.). Поскольку неоправданное увеличение вложений в один из факторов может негативно сказаться на всем результате деятельности того или иного региона, следует разработать методический порядок обоснования форм и процедур государственного участия в инвестиционных проектах перерабатывающих производств инновационного типа.

B-третьих, изучение инноваций как социального процесса тесно связано с развитием общества, уровнем жизни и существующей институциональной системой, регулирующей тенденции развития секторов экономики. 


\section{СПИСОК ЛИТЕРАТУРЫ}

Портер, М. Конкуренция : пер. с англ. / М. Портер. - М. : Вильямс, 2006. -610 с.

Реализация кластерной политики // Министерство экономического развития Российской Федерации. - Электрон. текстовые дан. - Режим доступа: http://economy.gov.ru/minec/activity/ sections/innovations/politic (дата обращения: 15.03.2021). - Загл. с экрана.

Российская кластерная обсерватория // НИУ ВШЭ. Электрон. текстовые дан. - Режим доступа: https://cluster.hse.ru (дата обращения: 15.03.2021). - Загл. с экрана.

Федеральная служба государственной статистики. Электрон. текстовые дан. - Режим доступа: https://www.gks.ru (дата обращения: 15.03.2021). Загл. с экрана.

Audretsch, D. B. R\&D Spillovers and the Geography of Innovation and Production / D. B. Audretsch, M. P. Feldman // American Economic Review. 1996. - Vol. 86 (3). - P. 630-640.

Bekes, G. Clusters, Science Parks and Regional Development (Strategies and Policies in Hungary) / G. Bekes // Presentation at UNECT TOS-ICP Geneva 14 February, 2008.

Global Innovation Index for 2018-2020 (2021). Electronic text data. - Mode of access: https:// www.globalinnovationindex.org (date of access: 15.03.2021). - Загл. с экрана.

Jaffe, A. B. Geographic Localization of Knowledge Spilovers as Evidenced by Patent Citations / A. B. Jaffe, M. Trajtenberg, R. Hendersen // Quarterly Journal of Economics. - 1993. № 434. - P. 578-598.

Sakhariyeva, A. S. An Innovative Cluster as a Remedy Against the Dutch Disease / A. S. Sakhariyeva // Proceedings of the $21^{\text {st }}$ International Business Information Management Association Conference "Vision2020: Innovation, Development
Sustainability, and Economic Growth". - Vienna : [s. n.], 2013. -P. 1007-1018.

\section{REFERENCES}

Porter, M. Konkurencija [On Competition]. Moscow, Williams Publ., 2006. 610 p.

Realizacija klasternoj politiki [Implementation of Cluster Policy]. Ministerstvo jekonomicheskogo razvitija Rossijskoj Federacii [Ministry of Economic Development of the Russian Federation]. URL: http:/economy.gov.ru/minec/activity/sections/ innovations/politic (accessed 15 March 2021).

Rossijskaja klasternaja observatorija [Russian Cluster Observatory]. URL: https://cluster. hse.ru (accessed 15 March 2021).

Federalnaya sluzhba gosudarstvennoy statistiki [Federal State Statistics Service]. URL: https:// www.gks.ru (accessed 15 March 2021).

Audretsch D.B., Feldman M.P. R\&D Spillovers and the Geography of Innovation and Production. American Economic Review, 1996, vol. 86(3),pp. 630-640.

Bekes G. Clusters, Science Parks and Regional Development (Strategies and Policies in Hungary). Presentation at UNECT TOS-ICP Geneva 14 February, 2008.

Global Innovation Index for 2018 - 2020 (2021). URL: https://www.globalinnova-tionindex.org (accessed 15 March 2021).

Jaffe, A.B., Trajtenberg M., Hendersen R. Geographic Localization of Knowledge Spilovers as Evidenced by Patent Citations. Quarterly Journal of Economics, 1993, no. 434, pp. 578-598.

Sakhariyeva, A. S. An Innovative Cluster as a Remedy Against the Dutch Disease. Proceedings of the $21^{\text {st }}$ International Business Information Management Association Conference "Vision2020: Innovation, Development Sustainability, and Economic Growth”. Vienna, 2013, pp. 1007-1018.

\section{Information About the Author}

Marina S. Lapina, Senior Lecturer, Department of Applied Informatics and Mathematical Methods in Economics, Volgograd State University, Prosp. Universitetsky, 100, 400062 Volgograd, Russian Federation, lapina.m.s@mail.ru, https://orcid.org/0000-0002-6031-199X

\section{Информация об авторе}

Марина Сергеевна Лапина, старший преподаватель кафедры прикладной информатики и математических методов в экономике, Волгоградский государственный университет, просп. Университетский, 100, 400062 г. Волгоград, Российская Федерация, lapina.m.s@mail.ru, https://orcid.org/0000-0002-6031-199X 